\title{
ASSESSMENT OF DERMATOLOGICAL CONDITIONS IN DIABETIC PATIENTS, ASSOCIATIONS WITH DEMOGRAPHIC VALUES AND METABOLIC COMPENSATION
}

\author{
Ksenija Kramica ${ }^{1}$, leva Ruza, MD1,2 \\ ${ }^{1}$ Riga Stradins University, ${ }^{2}$ Riga Eastern Clinical University Hospital clinic "Gailezers", Latvia.
}

\section{Introduction}

Diabetes mellitus (DM) is a group of metabolic diseases where prolonged hyperglycaemia provoke damaging impact on internal organs and the skin as well.

Comprehension of dermatological changes in DM, association with demographic values, metabolic compensation level $(\mathrm{HbA} 1 \mathrm{C})$ could help to define groups where skin complications may develop more often. That could be a usefull criteria to diagnose DM earlier.

\section{Objectives}

- To determine prevalence of skin pathological conditions in DM.

- To find out their association with demographic values and compensation level of disease.

\section{Methods}

A retrospective cohort study was performed.

Participants were randomly included from Internal Medicine clinic of Riga Eastern Clinical University Hospital.

Patient interviewing, observation and retrospective analysis of case files were performed for necessary data selection.

\section{Results}

- 151 patients were included.

- The mean age was 59.9 years (SD 15.9 years).

- Patients were divided into 3 age groups - group I (<=45 years) $19 \%$, group II (46-59 years) $25 \%$, group III (>=60 years) $56 \%$.

- Patients were divided into groups by DM duration, type and therapy - (0-5 years of DM) $27 \%$, (6-10 years) $23 \%$, (11-20 years) $34 \%$, (>20 years) 16\%; Type 1 DM 19\%, Type 2 DM 75\%, other (secondary) 6\%; patients who had insulin therapy (60\%) and patients who had peroral therapy or only diet (40\%).

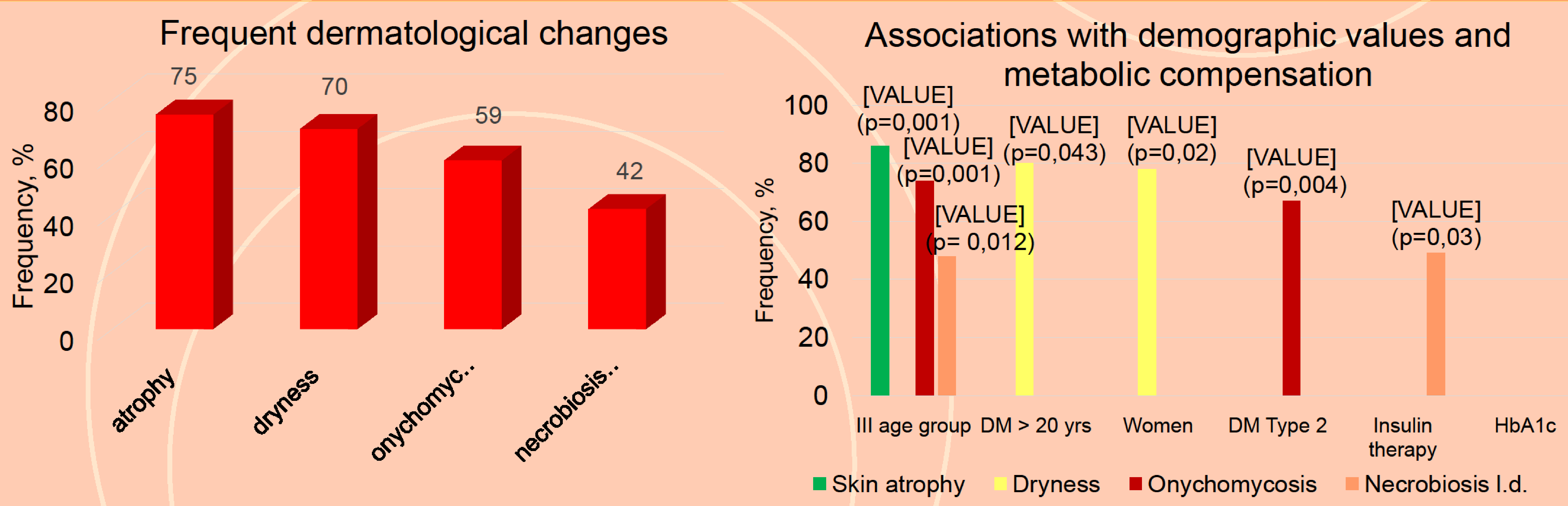

\section{Conclusions}

- Most common dermatological conditions in DM patients are atrophy, dryness, onychomycosis, necrobiosis lipoidica.

- Associations with age, gender, treatment, disease duration, DM type were defined.

- No skin changes were statistically significant with disease compensation level $(\mathrm{HbA} 1 \mathrm{c})$, but the reason may be relatively small amount of patients, insufficient data in some cases. More extensive studies are required.

References

WHO, Definition and diagnosis of diabetes mellitus and intermediate hyperglycemia, Report of a WHO/IDF Consultation, ๑ World Health Organization 2006 "Kliniskā Dermatoveneroloǵija», P.Vasariňš, A.Miltinš 1999, p.356-360

http://www.ncbi.nlm.nih.gov/pubmed/21762390

Abhishek Goyal, Sujeet Raina, Satinder S Kaushal, Vikram Mahajan, and Nand Lal Sharma PATTERN OF CUTANEOUS MANIFESTATIONS IN DIABETES MELLITUS, Indian J Dermatol. 2010 Jan-Mar; 55(1): 39-41. 